\begin{tabular}{|c|c|}
\hline Title & Effect of laser and/or electron beam irradiation on void swelling in SUS316L austenitic stainless steel \\
\hline Author(s) & Y ang, Subing; Y ang, Zhanbing; W ang, Hui; W atanabe, Seiichi; Shibay ama, Tamaki \\
\hline Citation & $\begin{array}{l}\text { Journal of nuclear materials, 488, 215-221 } \\
\text { https://doi.org/10.1016/.jnucmat.2017.03.002 }\end{array}$ \\
\hline Issue Date & $2017-05$ \\
\hline Doc URL & http:/hdl.handle.net/2115/73813 \\
\hline Rights & $\begin{array}{l}\text { (0) 2017, Elsevier. Licensed under the Creative Commons A ttribution-NonCommercial-NoDerivatives } 4.0 \\
\text { International http://creativecommons.org/icenses/by-nc-nd/4.0/ }\end{array}$ \\
\hline Rights(URL) & http://creativecommons.org/icenses/by-nc-nd/4.0/ \\
\hline Type & article (author version) \\
\hline File Information & Manuscript.pdf \\
\hline
\end{tabular}

Instructions for use 


\title{
Effect of Laser and/or Electron Beam Irradiation on Void Swelling in SUS316L Austenitic Stainless Steel
}

\author{
Subing Yang a, Zhanbing Yang a,b*, Hui Wang a, Seiichi Watanabe ${ }^{c}$, \\ Tamaki Shibayama $^{\mathrm{c}}$

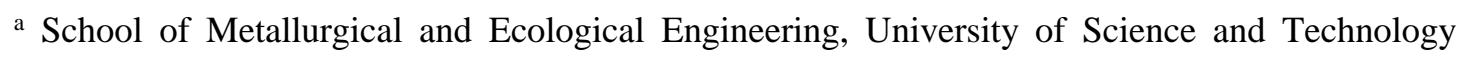 \\ Beijing, Beijing 100083, PR China; \\ ${ }^{b}$ State Key Laboratory of Advanced Metallurgy, University of Science and Technology Beijing, \\ Beijing 100083, PR China; \\ ${ }^{c}$ Center for Advanced Research of Energy and Materials, Faculty of Engineering, Hokkaido \\ University, Sapporo, Hokkaido 060-8628, Japan. \\ * Corresponding author. \\ E-mail address: yangzhanbing@ustb.edu.cn (Zhanbing Yang).
}

\section{Highlights}

- The temperature dependence of void swelling under simultaneous laser-electron dual-beam irradiation has been investigated.

- Pre-laser irradiation enhances void nucleation at temperatures from $573 \mathrm{~K}$ to 773 $\mathrm{K}$.

- Simultaneous laser-electron dual-beam irradiation suppresses void swelling in the temperature range of $573-773 \mathrm{~K}$.

\begin{abstract}
Large amounts of void swelling still limit the application of austenitic stainless steels in nuclear reactors due to radiation-induced lattice point defects. In this study, laser and/or beam irradiation was conducted in a temperature range of $573-773 \mathrm{~K}$ to explore the suppression of void swelling. The results show that during sequential laser-electron beam irradiation, the void nucleation is enhanced because of the vacancy clusters and void nuclei formed under pre-laser irradiation, causing greater void swelling than single electron beam irradiation. However, simultaneous laser-electron dual-beam irradiation exhibits an obvious suppression effect on void swelling due to the enhanced recombination between interstitials and vacancies in the temperature range of 573-773 K; especially at $723 \mathrm{~K}$, the swelling under simultaneous dual-beam irradiation is $0.031 \%$ which is only $22 \%$ of the swelling under electron beam irradiation $(0.137 \%)$. These results provide new insight into the suppression of
\end{abstract}


void swelling during irradiation.

Key words: Vacancy; Void swelling; Multi-quantum beam HVEM; Laser-electron dual-beam irradiation. 


\section{Introduction}

Austenitic stainless steels, such as $316 \mathrm{~L}$, are widely used for structural components in current light water reactors (LWR) and have been considered as the candidate structural material for some Gen-IV nuclear reactors because of their high mechanical properties coupled with reasonable corrosion resistance [1-4]. However, the large amount of void swelling, which causes changes in dimension, remains a major limitation for the performance of austenitic stainless steels [2,3], especially considering the enhancing effect of void swelling on other radiation-induced damage, such as embrittlement [5,6], creep [7] and irradiation-assisted stress corrosion cracking [4].

To develop nuclear reactor materials and prolong the lifetime of these components, significant effort has been directed to suppressing or decreasing irradiation-induced void swelling. For austenitic stainless steels, some methods, such as doping with trace elements [8,9], cold working [10,11] and the precipitation of dispersed phases [12], have been investigated in recent decades to increase the swelling resistance by designing self-healing microstructures $[3,13]$. However, thus far, these promising methods have in some ways remained undeveloped, such as the influence of the cold-work level on material properties [14,15], the determination of suitable additional elements to suppress void swelling $[8,16]$, and the effect of dispersed phase stability on void swelling [17]. Although ferritic/martensitic (F/M) stainless steels present excellent void swelling resistance [18-20] and are also potential candidates for structural materials $[1,3]$, there remain other issues to be resolved for them, especially microstructural instability, which is deleterious to mechanical and corrosive properties [1,21-23]. Therefore, it is essential to continue investigating the austenitic stainless steels and find new methods to suppress void swelling in these alloys.

In our previous work, void swelling in $316 \mathrm{~L}$ austenitic stainless steel was suppressed by laser-electron dual-beam irradiation at $723 \mathrm{~K}$ due to the enhanced recombination between interstitials and vacancies [24]. In contrast to the other methods mentioned above, which suppress void swelling through increasing the void 
resistance of austenitic stainless steels before irradiation, simultaneous laser-electron dual-beam irradiation is considered to directly suppress void swelling during irradiation and requires no change to the properties of the austenitic stainless steels before irradiation. This option is convenient and provides a new approach to the suppression of void swelling. However, for laser-electron dual-beam irradiation, the temperature dependence of void number density, size and void swelling and the mechanism underlying them remain unidentified. Consequently, it is necessary to investigate the effect of laser-electron dual-beam irradiation on void swelling behaviour at other operation temperatures for austenitic stainless steels.

In this paper, over the temperature range of 573-773 $\mathrm{K}$ associated with the operation temperature for austenitic stainless steels [3], the effect of laser-electron dual-beam irradiation on void formation is investigated using a multi-quantum beam high-voltage electron microscope (Multi-Quantum Beam HVEM) to explore a new method to suppress void swelling.

\section{Experimental}

The material used in this study was commercial SUS316L austenitic stainless steel, and the chemical composition of the material is listed in Table 1. Disk specimens 3 $\mathrm{mm}$ in diameter were punched from sheets after mechanical polishing to $0.15 \mathrm{~mm}$ thick. Foil specimens for transmission electron microscopy were prepared by twin jet electropolishing in a solution of $95 \%$ acetic acid and 5\% perchloric acid (volume\%).

\section{Table 1}

Chemical composition of SUS316L steel (mass\%)

\begin{tabular}{cccccccccccc}
\hline $\mathrm{C}$ & $\mathrm{Si}$ & $\mathrm{Mn}$ & $\mathrm{P}$ & $\mathrm{S}$ & $\mathrm{Ni}$ & $\mathrm{Cr}$ & $\mathrm{Mo}$ & $\mathrm{V}$ & $\mathrm{Al}$ & $\mathrm{N}$ & $\mathrm{Fe}$ \\
\hline 0.013 & 0.20 & 1.28 & 0.024 & 0.0010 & 13.32 & 17.24 & 2.04 & 0.04 & 0.014 & 0.0396 & Bal. \\
\hline
\end{tabular}

To identify the effect of laser and/or electron beam irradiation on void swelling, the results under laser-electron dual-beam irradiation and sequential laser-electron irradiation were compared with the results obtained from electron beam irradiation, which is treated as a standard in this study due to the thorough investigation of void 
swelling behaviour under electron-beam irradiation. Therefore, three series of irradiation (electron irradiation ( $\mathrm{e}^{-}$irr.), sequential laser-electron irradiation $\left(\mathrm{L} \rightarrow \mathrm{e}^{-}\right.$irr.) and laser-electron dual-beam irradiation ( $\mathrm{L}+\mathrm{e}^{-}$irr.)) were conducted with multi-quantum beam HVEM (Laser: Nd:YAG (Continuum, Inlite II-20); HVEM: JEOL, JEM-ARM1300) at temperatures from $573 \mathrm{~K}$ to $773 \mathrm{~K}$ at $50 \mathrm{~K}$ intervals. During electron beam irradiation at $1250 \mathrm{kV}$, the mean damage rate was $2 \times 10^{-3} \mathrm{dap} / \mathrm{s}$, corresponding to a dose of $3.6 \mathrm{dpa}$ for $30 \mathrm{~min}$. For pulsed laser beam irradiation, the laser parameters were $532 \mathrm{~nm}, 2 \mathrm{~Hz}$ and $24 \mathrm{~mJ} / \mathrm{cm}^{2}$ for the central wavelength, repetition rate and energy density, respectively. The details for all three types of irradiation are shown in Table 2. In addition, the thickness of the irradiated area was measured about $300 \mathrm{~nm}$ by the method of contamination spot separation.

Table 2

Details of the three experimental irradiation procedures

\begin{tabular}{|c|c|c|}
\hline Types & Temperatures $(\mathrm{K})$ & Procedures \\
\hline $\mathrm{e}^{-}$irr. & $573-773$ & Single electron beam irradiation for $30 \mathrm{~min}$ \\
\hline $\mathrm{L} \rightarrow \mathrm{e}^{-}$irr. & $573-773$ & $\begin{array}{l}\text { Single laser beam irradiation for } 30 \mathrm{~min} \text { followed by electron } \\
\text { irradiation for } 30 \mathrm{~min} .\end{array}$ \\
\hline $\mathrm{L}+\mathrm{e}^{-}$irr. & $573-773$ & Simultaneous laser-electron dual-beam irradiation for $30 \mathrm{~min}$ \\
\hline
\end{tabular}

To analyse the void swelling in the interior of the materials, the surfaces of the specimens were removed from both sides to a thickness of approximately $150 \mathrm{~nm}$ using a precision ion polishing system (PIPS) (Gatan 691.CS) under the conditions of $\mathrm{a} \pm 4^{\circ}$ angle, $4 \mathrm{keV}$ energy and $-113 \mathrm{~K}$ temperature.

Before and after PIPS, void observation was performed by transmission electron microscope (Tecnai $G^{2}$ F20). For each irradiation condition, the void size, number density and swelling were measured and calculated in five fields with each field in a size of $485 \mathrm{~nm} \times 485 \mathrm{~nm}$, then the average value and standard deviation were obtained.

\section{Results}

Typical microstructures of $316 \mathrm{~L}$ austenitic stainless steels under different irradiation conditions are shown in Fig. 1. Voids formed at different temperatures and 
under different irradiation styles show great differences in size and number density.

(Figure 1)

The temperature dependence of void number density, mean size and swelling under the three irradiation series are presented in Fig. 2(a), (b) and (c), respectively. As the irradiation temperature increases, the void number density first increases followed by a marked decrease after reaching a maximum at $673 \mathrm{~K}$. The maximum values are 13.4 $\times 10^{20} \mathrm{~m}^{-3}, 15.8 \times 10^{20} \mathrm{~m}^{-3}$, and $18.6 \times 10^{20} \mathrm{~m}^{-3}$ for $\mathrm{e}^{-}$irr., $\mathrm{L}+\mathrm{e}^{-}$irr. and $\mathrm{L} \rightarrow \mathrm{e}^{-}$irr., respectively. Moreover, in the temperature range of $573-773 \mathrm{~K}$, the void number densities under both $\mathrm{L} \rightarrow \mathrm{e}^{-}$irr. and $\mathrm{L}+\mathrm{e}^{-}$irr. are higher than under $\mathrm{e}^{-}$irr., which is in good agreement with our previous work at $723 \mathrm{~K}$ [24].

In Fig. 2(b), the void mean sizes in specimens $\mathrm{e}^{-}$irr., $\mathrm{L}+\mathrm{e}^{-}$irr. and $\mathrm{L} \rightarrow \mathrm{e}^{-}$irr. increase with increasing irradiation temperature, from $3.7 \mathrm{~nm}, 3.2 \mathrm{~nm}$ and $2.8 \mathrm{~nm}$ at $573 \mathrm{~K}$ to $14.5 \mathrm{~nm}, 12.1 \mathrm{~nm}$ and $8.6 \mathrm{~nm}$ at $773 \mathrm{~K}$, respectively. Although the void formation tendency under $\mathrm{L} \rightarrow \mathrm{e}^{-}$irr. and $\mathrm{L}+\mathrm{e}^{-}$irr. is similar to the tendency under $\mathrm{e}^{-}$irr., some significant differences in their values do exist. When compared at the same temperature, it is clear that the void mean sizes under $\mathrm{L} \rightarrow \mathrm{e}^{-}$irr. and especially under $\mathrm{L}+\mathrm{e}^{-}$irr. are notably smaller than under $\mathrm{e}^{-}$irr.

(Figure 2)

The statistical results of void swelling, representing the comprehensive results for void mean size and number density, are shown in Fig. 2(c). For the dependence of void swelling on temperature, $\mathrm{e}^{-}$irr. and $\mathrm{L} \rightarrow \mathrm{e}^{-}$irr. show a similar curve, and both indicate a peak swelling, $0.137 \%$ for $\mathrm{e}^{-}$irr. and $0.197 \%$ for $\mathrm{L} \rightarrow \mathrm{e}^{-}$irr. at $723 \mathrm{~K}$. Although the void swelling under $\mathrm{L}^{-} \mathrm{e}^{-}$irr. increases with increasing irradiation temperature, the value is small, only $0.041 \%$ at $773 \mathrm{~K}$. Furthermore, when the swelling under the three irradiation series at the same temperature is compared, the tendency in the temperature range of $573-773 \mathrm{~K}$ is always $\mathrm{L}+\mathrm{e}^{-}$irr. $<\mathrm{e}^{-}$irr. $<\mathrm{L} \rightarrow \mathrm{e}^{-}$irr. Especially at $723 \mathrm{~K}$, the void swelling under $\mathrm{L}+\mathrm{e}^{-}$irr. is $0.031 \%$ which is only $22 \%$ and $16 \%$, respectively, of the void swelling under $\mathrm{e}^{-}$irr. (0.137\%) and $\mathrm{L} \rightarrow \mathrm{e}^{-}$irr. $(0.197 \%)$. This result demonstrates that over the entire temperature range of 573-773 $\mathrm{K}, \mathrm{L}+\mathrm{e}^{-}$irr. has a suppressing effect on void swelling, which is consistent with our 
previous work at $723 \mathrm{~K}$ [24].

\section{Discussion}

\subsection{Void number density under three irradiation series}

Void formation, that is, the void nucleation and growth, is governed by point defects introduced through irradiation [25]. For void nucleation, it is necessary to reach a definite critical vacancy concentration depending on temperature [26]. It should be pointed out that at $573 \mathrm{~K}$, because of low diffusivity of vacancy, void size is quite small under each irradiation, therefore the number of visible voids is small, and the difference of void number density under each irradiation is quite small, as shown in Fig. 2(a). Below $673 \mathrm{~K}$, the void nucleation under three series irradiations is enhanced with the increasing temperature, which is attributed to the increasing vacancy diffusivity. However, void number densities show an intensely decreasing trend as the irradiation temperature increases further, which may be related to the decrease of supersaturated vacancy concentration as the result of preferential vacancies flow towards point defect sinks [17,27].

4.2 Void growth under three irradiation series

The void growth is determined by the net rate of vacancies flowing into the void [28]. When temperature increases, the vacancy diffusivity and flux into voids increase, resulting in an expedited void growth rate, as shown in Fig. 2(b). Compared with electron irradiation at the same irradiation temperature, the void mean size under $\mathrm{L} \rightarrow$ $\mathrm{e}^{-}$irr. is smaller because the increase in void number density decreases the number of vacancies per void.

For $\mathrm{L}+\mathrm{e}^{-}$irr., not only at $723 \mathrm{~K}$ but also in the whole temperature range of $573-773$ $\mathrm{K}$, the void mean size is always the smallest compared with the other two irradiation series. This result indicates that, as at $723 \mathrm{~K}$ [24], at other temperatures, the recombination of vacancies and interstitials is also enhanced under $\mathrm{L}+\mathrm{e}^{-}$irr. which delays the void growth and lead to a smaller void size than that under the $\mathrm{e}^{-}$irr. and $\mathrm{L}$ $\rightarrow \mathrm{e}^{-}$irr.. Moreover, as shown in Fig. 2(b), the larger difference of the void mean size 
between $\mathrm{L}+\mathrm{e}^{-}$irr.and $\mathrm{e}^{-}$irr. indicates that $\mathrm{L}+\mathrm{e}^{-}$irr. performs a stronger enhancement of point defects recombination at higher temperature.

(Figure 3)

To easily distinguish the differences in void size distribution among the three irradiation series, voids formed at $673 \mathrm{~K}, 723 \mathrm{~K}$ and $773 \mathrm{~K}$, where the voids are relatively large, are classified with regard to the void size, as shown in Fig. 3. With the increase of temperature, more voids belonging to regimes 4 and 5 are observed, which is in good agreement with the temperature dependence of the void mean size (shown in Fig. 2(b)).

For $\mathrm{L} \rightarrow \mathrm{e}^{-}$irr., due to the enhanced nucleation, the number of voids belonging to regimes 1 and 2 is much larger than that under $\mathrm{e}^{-}$irr. as shown in Fig. 3. The number of large void belonging to regimes 4 and 5 is close to the number under $\mathrm{e}^{-}$irr.. Because during $\mathrm{L} \rightarrow \mathrm{e}^{-}$irr., the voids nucleated under pre pulse-laser irradiation may preferentially grow up during the sequential $\mathrm{e}^{-}$irr., subsequently, some large voids (> $12 \mathrm{~nm}$ ) form.

For $\mathrm{L}+\mathrm{e}^{-}$irr., rare large voids formed, resulting in the smallest void mean size compared with the other irradiations, which reconfirms the prominent effect of $\mathrm{L}^{-} \mathrm{e}^{-}$ irr. on delaying the void growth.

Moreover, although not shown in Fig. 3, the void size distributions at $573 \mathrm{~K}$ and $623 \mathrm{~K}$ exhibit the same trends mentioned above.

\subsection{Void swelling under three irradiation series}

As a comprehensive result, void swelling is determined by both void mean size and void number density. Due to the decreasing void number density and increasing void size with increasing irradiation temperature, the temperature dependence of void swelling under both $\mathrm{e}^{-}$irr. and $\mathrm{L} \rightarrow \mathrm{e}^{-}$irr. show a curve and indicate a maximum at 723 $\mathrm{K}$ (shown in Fig. 2). Although $\mathrm{L}+\mathrm{e}^{-}$irr. exhibits a similar tendency to $\mathrm{e}^{-}$irr. and $\mathrm{L} \rightarrow \mathrm{e}^{-}$ irr. in the temperature dependence of void number density and mean size, the temperature dependence of void swelling under $\mathrm{L}+\mathrm{e}^{-}$irr. does not show a decreasing tendency, even at $773 \mathrm{~K}$. This result may be because the decrease in void number 
density under $\mathrm{L}+\mathrm{e}^{-}$irr. at high temperature is not as sharp as under $\mathrm{e}^{-}$irr. or $\mathrm{L} \rightarrow \mathrm{e}^{-}$irr. due to the lower sink strength under $\mathrm{L}+\mathrm{e}^{-}$irr. [24] for the point defects to annihilate.

Considering the void number density (Fig. 2(a)) and void size distribution (Fig. 3), it is easy to determine that the number of voids belonging to the largest void regime under $\mathrm{L} \rightarrow \mathrm{e}^{-}$irr. is close to the number under $\mathrm{e}^{-}$irr. However, the number of voids belonging to the regime of 0-8 $\mathrm{nm}$ under $\mathrm{L} \rightarrow \mathrm{e}^{-}$irr. is much larger than that under $\mathrm{e}^{-}$irr. As a result, the void swelling under $\mathrm{L} \rightarrow \mathrm{e}^{-}$irr. is higher than under $\mathrm{e}^{-}$irr., which is found to be consistent throughout the temperature range.

For $\mathrm{L}+\mathrm{e}^{-}$irr., while the number of voids is larger than under $\mathrm{e}^{-}$irr., voids belonging to the large void regime are rare, leading to the lowest swelling compared with the other two types of irradiation. Consequently, during $\mathrm{L}+\mathrm{e}^{-}$irr., while the void nucleation is enhanced due to the high vacancy concentration, the void growth is greatly delayed because of the enhanced recombination between interstitials and vacancies; as a result, the void swelling is remarkably suppressed under $\mathrm{L}+\mathrm{e}^{-}$irr. This suppressing effect and mechanism are shown to be tenable throughout the temperature range of $573-773 \mathrm{~K}$.

4.4 Void formation behaviour in the interior of specimens under three irradiation series

During pulsed laser irradiation, rapid heating and quenching occur on the surface of the specimen, introducing excess vacancies into the surface; the excess vacancies then diffuse into the interior of specimens due to the conversion gradient of the vacancies $[29,30]$. Considering that the difference between surface and interior in introducing vacancy may cause different void swelling behaviours, investigating the void swelling behaviour in the interior of the material is helpful to further confirm and understand the suppressing effect of $\mathrm{L}+\mathrm{e}^{-}$irr. on void swelling.

(Figure 4)

The microstructure and statistical results of void swelling, after removing the surface, are shown in Fig. 4 and Fig. 5, respectively. Because some larger voids formed in the zone around the surface are removed by PIPS, the voids observed in the 
specimens are reduced in both size and number compared with the voids before PIPS (shown in Fig. 1); however, the tendency among the three irradiation series remains, i.e., $\mathrm{e}^{-}$irr. $<\mathrm{L}+\mathrm{e}^{-}$irr. $<\mathrm{L} \rightarrow \mathrm{e}^{-}$irr. in void number density (except at $623 \mathrm{~K}$ ), $\mathrm{L}+\mathrm{e}^{-}$irr. $<$ $\mathrm{L} \rightarrow \mathrm{e}^{-}$irr. $<\mathrm{e}^{-}$irr. in void size, and $\mathrm{L}+\mathrm{e}^{-}$irr. $<\mathrm{e}^{-}$irr. $<\mathrm{L} \rightarrow \mathrm{e}^{-}$irr. in void swelling. This result suggests that laser irradiation has a similar effect on the void swelling behaviour in the interior of the matrix to the one mentioned in sections 4.1-4.3, including enhancing nucleation during $\mathrm{L} \rightarrow \mathrm{e}^{-}$irr., and suppressing void swelling during $\mathrm{L}+\mathrm{e}^{-}$irr.. Consequently, it is confirmed that $\mathrm{L}+\mathrm{e}^{-}$irr. exerts a suppressing effect on void swelling throughout the irradiated area, both on the surface and in the interior.

(Figure 5)

\section{Conclusions}

For the dependence of void swelling on temperature, $\mathrm{e}^{-}$irr. and $\mathrm{L} \rightarrow \mathrm{e}^{-}$irr. indicate a peak swelling at $723 \mathrm{~K}$; the void swelling under $\mathrm{L}+\mathrm{e}^{-}$irr. increases with increasing irradiation temperature.

Furthermore, under $\mathrm{L} \rightarrow \mathrm{e}^{-}$irr., vacancy clusters and void nuclei are formed due to the excess vacancies introduced by pre-laser irradiation, causing enhanced void nucleation and increased void swelling in the temperature range of 573-773 K. However, compared with single electron irradiation, L+e ${ }^{-}$irr. exhibits an obvious suppressing effect on void swelling because of the enhanced recombination between interstitials and vacancies at temperatures from $573 \mathrm{~K}$ to $773 \mathrm{~K}$, especially at $723 \mathrm{~K}$, the void swelling under $\mathrm{L}+\mathrm{e}^{-}$irr. is $0.031 \%$, only $22 \%$ of the void swelling under $\mathrm{e}^{-}$irr.; Moreover, this suppressing effect is tenable both on the surface and in the interior of the material. The results provide a new approach to suppressing void swelling in the temperature range of $573-773 \mathrm{~K}$.

\section{Acknowledgements}

The authors are grateful to Mr. K. Ohkubo, Mr. T. Tanioka, Dr. R.X. Yu and Dr. Y.H. Lei for their help in operating the laser-HVEM system. The authors are also grateful to Dr. J. Zhang and Dr. M.M. Song for their helpful discussions. This work was 
supported by the National Natural Science Foundation of China (51471027), the Fundamental Research Funds for the Central Universities, and Open Funds of State Key Laboratory of Advanced Metallurgy (KF14-03). 


\section{References}

[1] K.L. Murty, I. Charit, Structural materials for Gen-IV nuclear reactors: Challenges and opportunities, J. Nucl. Mater. 383(2008) 189-195.

[2] P. Yvon, F. Carré, Structural materials challenges for advanced reactor systems, J. Nucl. Mater. 385(2009) 217-222.

[3] C.R.F. Azevedo, Selection of fuel cladding material for nuclear fission reactors, Eng. Fall. Anal. 18(2011) 1943-1962.

[4] S.J. Zinkle, G.S. Was, Materials challenges in nuclear energy, Acta Mater. 61(2013) 735-758.

[5] V.S. Neustroev, F.A. Garner, Severe embrittlement of neutron irradiated austenitic steels arising from high void swelling, J. Nucl. Mater. 386-388(2009) 157-160.

[6] S.I. Porollo, A.N. Vorobjev, Y.V. Konobeev, A.M. Dvoriashin, V.M. Krigan, N.I. Budylkin, E.G. Mironova, F.A. Garner, Swelling and void-induced embrittlement of austenitic stainless steel irradiated to $73-82$ dpa at $335-365^{\circ} \mathrm{C}$, J. Nucl. Mater. 258-263(1998) 1613-1617.

[7] F.A. Garner, M.B. Toloczko, Irradiation creep and void swelling of austenitic stainless steels at low displacement rates in light water energy systems, J. Nucl. Mater. 251(1997) 252-261.

[8] T. Kato, H. Takahashi, M. Izumiya, Effects of systematic modification with oversized elements on void formation in 316L austenitic stainless steel under electron irradiation, Mater. Trans. 32(10) (1991) $921-930$

[9] T. Okita, W. G. Wolfer, F. A. Garner, N. Sekimura, Effects of titanium additions to austenitic ternary alloys on microstructural evolution and void swelling, Philos. Mag. 85(18) (2005) 2033-2048. [10] Y. Murase, J. Nagakawa, N. Yamamoto, H. Shiraishi, Effect of cold work on void swelling in proton irradiated Fe-15Cr-20Ni ternary alloys, J. Nucl. Mater. 258(1) (1998) 1639-1643.

[11] F.A. Garner, C.A. Black, D.J. Edwards, Factors which control the swelling of Fe-Cr-Ni ternary austenitic alloys, J. Nucl. Mater. 245(1997) 124-130.

[12] E. Wakai, N. Hashimoto, J.P. Robertson, T. Sawai, A. Hishinuma, Swelling of cold-worked austenitic stainless steels irradiated in HFIR under spectrally tailored conditions, J. Nucl. Mater. 307-311(2002) 352-356.

[13] S. J. Zinkle, J. T. Busby. Structural materials for fission and fusion energy, Mater. Today 12(11) (2009) 12-19. 
[14] E.R. Gilbert, F.A. Garner, The influence of cold-work level on the irradiation creep and swelling of AISI 316 stainless steel irradiated as pressurized tubes in the EBR-II fast reactor, J. Nucl. Mater. 367-370(2007) 954-959.

[15] V.D. Vijayanand, P. Parameswaran, M. Nandagopal, S. Panneer Selvi, K. Laha, M.D. Mathew, Effect of prior cold work on creep properties of a titanium modified austenitic stainless steel, J. Nucl. Mater. 438(2013) 51-57.

[16] Y. Sekio, S. Yamashita, N. Sakaguchi, H. Takahashi, Void denuded zone formation for Fe-15Cr-15Ni steel and PNC316 stainless steel under neutron and electron irradiations, J. Nucl. Mater. 458(2015) 355-360.

[17] N. Akasaka, K. Hattori, S. Onose, S. Ukai, Effect of temperature change on void swelling in P, Ti-modified 316 stainless steel, J. Nucl. Mater. 271\&272 (1999) 370-375.

[18] F.A. Garner, M.B. Toloczko, B.H. Sencer, Comparison of swelling and irradiation creep behavior of fcc-austenitic and bcc-ferritic/martensitic alloys at high neutron exposure, J. Nucl. Mater. 276(2000) 123-142.

[19] R.L. Klueh, Elevated temperature ferritic and martensitic steels and their application to future nuclear reactors, Inter. Mater. Rev. 50(5) (2005) 287-310.

[20] T. Chen, E. Aydogan, J.G. Gigax, D. Chen, J. Wang, X. Wang, S. Ukai, F.A. Garner, L. Shao, Microstructural changes and void swelling of a $12 \mathrm{Cr}$ ODS ferritic-martensitic alloy after high-dpa self-ion irradiation, J. Nucl. Mater. 467(2015) 42-49.

[21] M.K. Miller, D.T. Hoelzer, E.A. Kenik, K.F. Russell, Stability of ferritic MA/ODS alloys at high temperatures, Intermetallics 13(2005) 387-392.

[22] T. Yamashiro, S. Ukai, N. Oono, S. Ohtsuka, T. Kaito, Microstructural stability of 11Cr ODS steel, J. Nucl. Mater. 472(2016) 247-251.

[23] T. Yamashiro, S. Ukai, N. Oono, S. Ohtsuka, T. Kaito, Microstructural stability of 11Cr ODS steel, J. Nucl. Mater. 472(2016) 247-251.

[24] Z. Yang, S. Watanabe, T. Kato, The Irradiation effect of a simultaneous laser and electron dual-beam on void formation, Sci. Rep. 3(2013).

[25] Y. Sekio, S. Yamashita, N. Sakaguchi, H. Takahashi, Effect of additional minor elements on accumulation behavior of point defects under electron irradiation in austenitic stainless steels, Mater. Trans. 55(3) (2014) 438-442. 
[26] T. Yoshiie, X.Z. Cao, K. Sato, K. Miyawaki, Q. Xu, Point defect processes during incubation period of void growth in austenitic stainless steels, Ti-modified 316SS, J. Nucl. Mater. 417(2011) 968-971.

[27] H Takahashi, N Hashimoto. Radiation-induced segregation and grain boundary migration in Fe-Cr-Ni model alloy under irradiation. Materials Transactions, 1993, 34(11):1027-1030.

[28] A.V. Kozlov, I.A. Portnykh, L.A. Skryabin, E.A. Kinev, Temperature effect on characteristics of void population formed in the austenitic steel under neutron irradiation up to high damage dose, J. Nucl. Mater. 307-311 (2002) 956-960.

[29] J. Dutta Majumdar, R. Galun, B.L. Mordike, I. Manna, Effect of laser surface melting on corrosion and wear resistance of a commercial magnesium alloy, Mater. Sci. Eng. A 361(2003) 119-129.

[30] Z. Yang, N. Sakaguchi, S. Watanabe, M. Kawai, Dislocation loop formation and growth under in situ laser and/or electron irradiation, Sci. Rep. 1(2011).

\section{Figure captions}

Figure 1 Void micrographs under different irradiation conditions. (a) (e) $\mathrm{e}^{-}$irr.; (f) (j) L $\rightarrow \mathrm{e}^{-}$irr.; (k) (o) $\mathrm{L}+\mathrm{e}^{-}$irr.

Figure 2 Statistical results for void swelling under three irradiation series in the temperature range of 573-773 K. (a) Void number density. (b) Void size. (c) Void swelling. The error bar indicates the standard deviation.

Figure 3 Void size distribution under three irradiation series. (a) $673 \mathrm{~K}$, (b) $723 \mathrm{~K}$, and (c) $773 \mathrm{~K}$.

Void size is classified into five regimes, $1: 0-4 \mathrm{~nm} ; 2: 4-8 \mathrm{~nm} ; 3: 8-12 \mathrm{~nm} ; 4: 12-16 \mathrm{~nm}$; and 5: $\geq 16 \mathrm{~nm}$. The error bar indicates the standard deviation.

Figure 4 Void micrographs after ion-milling under different irradiation conditions. (a) (e) $\mathrm{e}^{-}$irr.; (f) (j) L $\rightarrow \mathrm{e}^{-}$irr.; (k) (o) L+e- irr.

Figure 5 Statistical results of void swelling under three irradiation series after PIPS. (a) Void number density. (b) Void mean size. (c) Void swelling. The error bar indicates the standard deviation. 

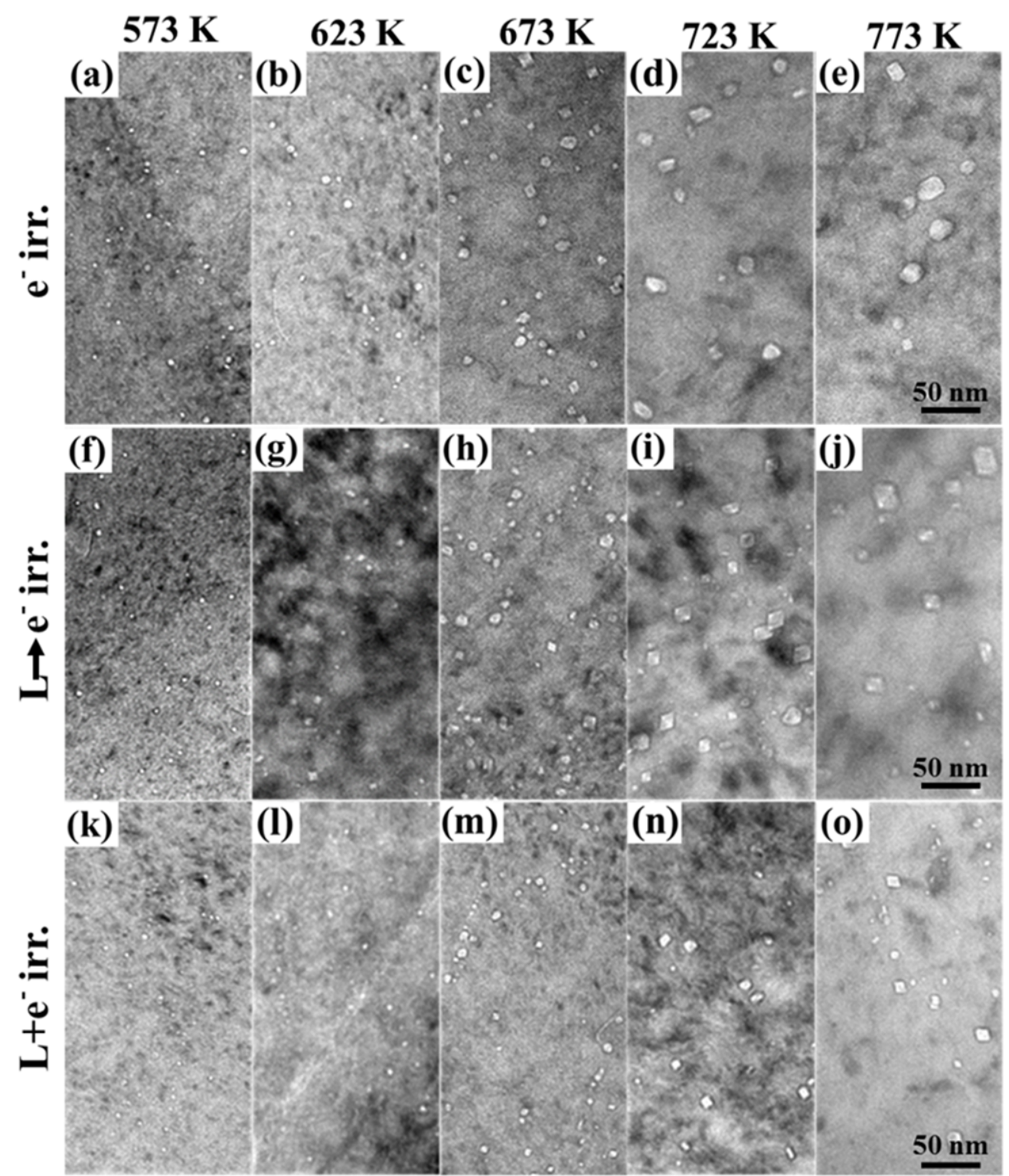

Figure 1

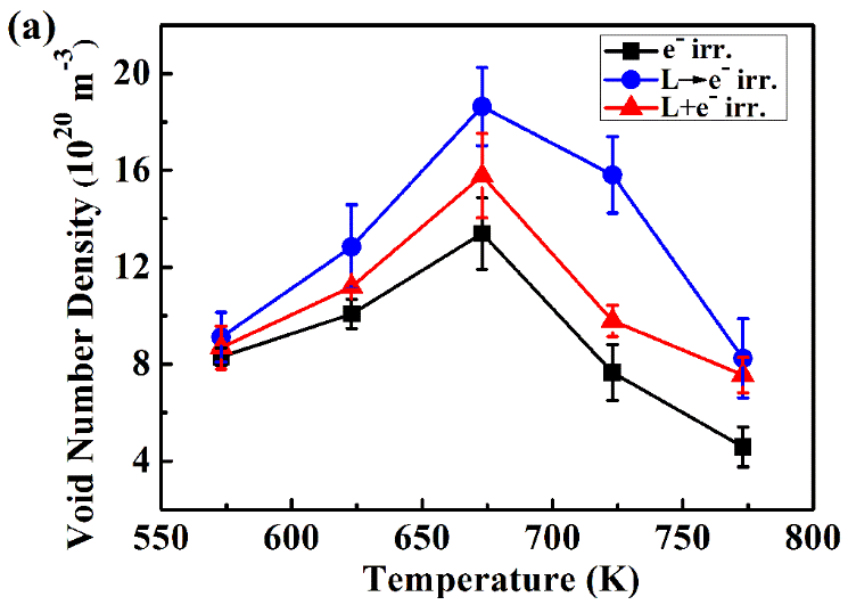

Figure 2(a) 


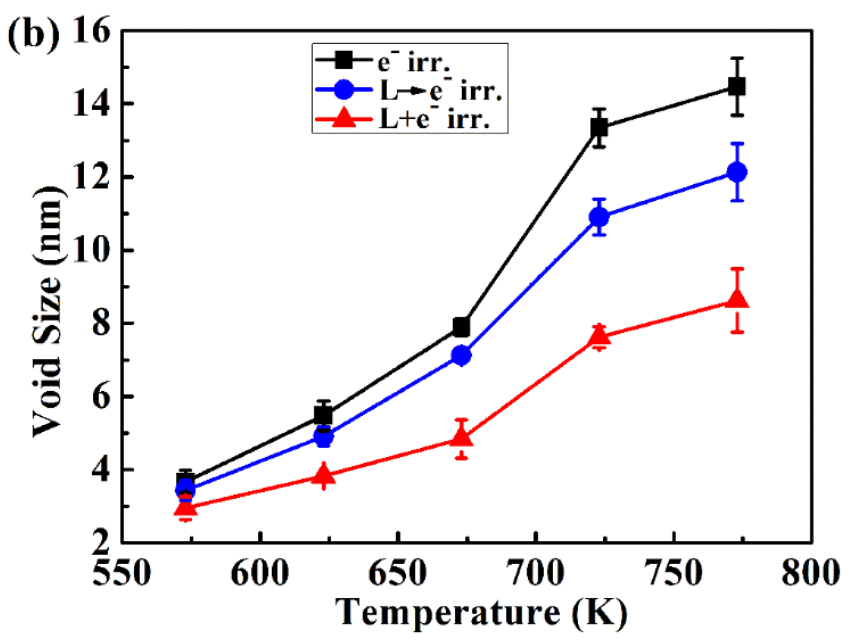

Figure 2(b)

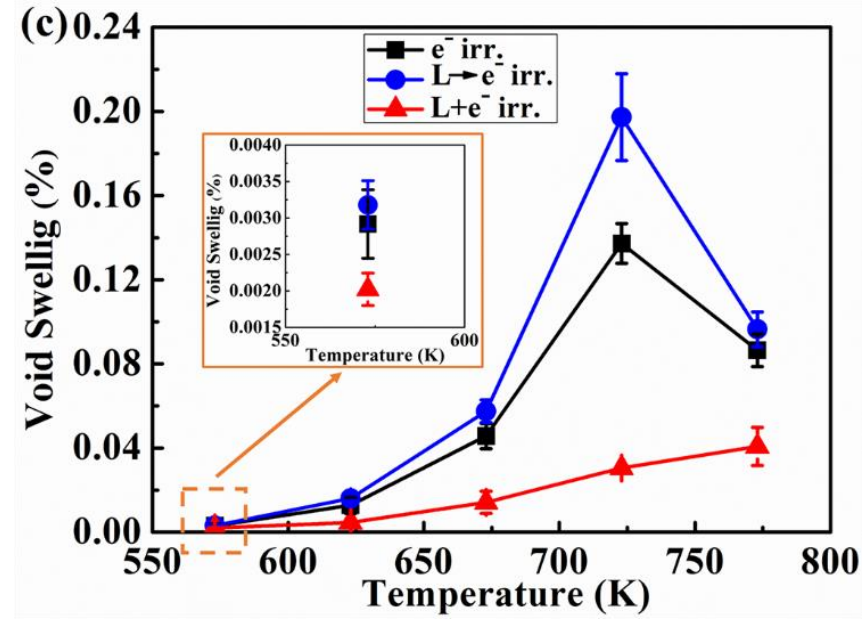

Figure 2(c)

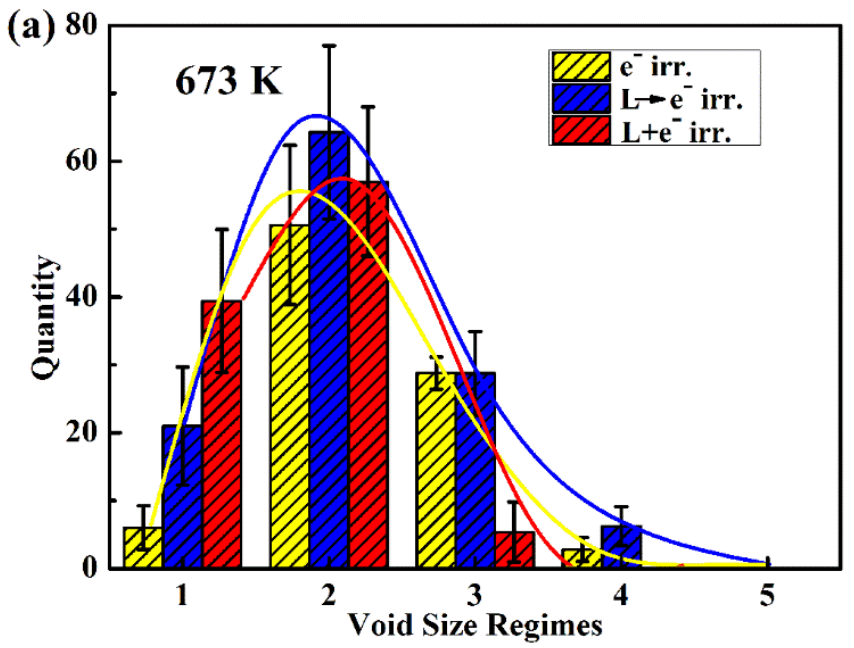

Figure 3(a) 


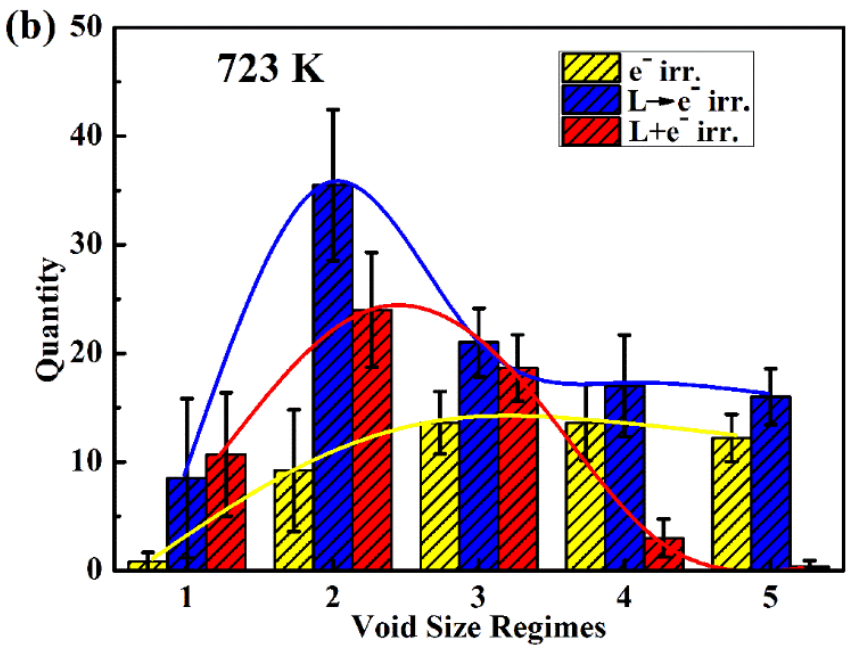

Figure 3(b)

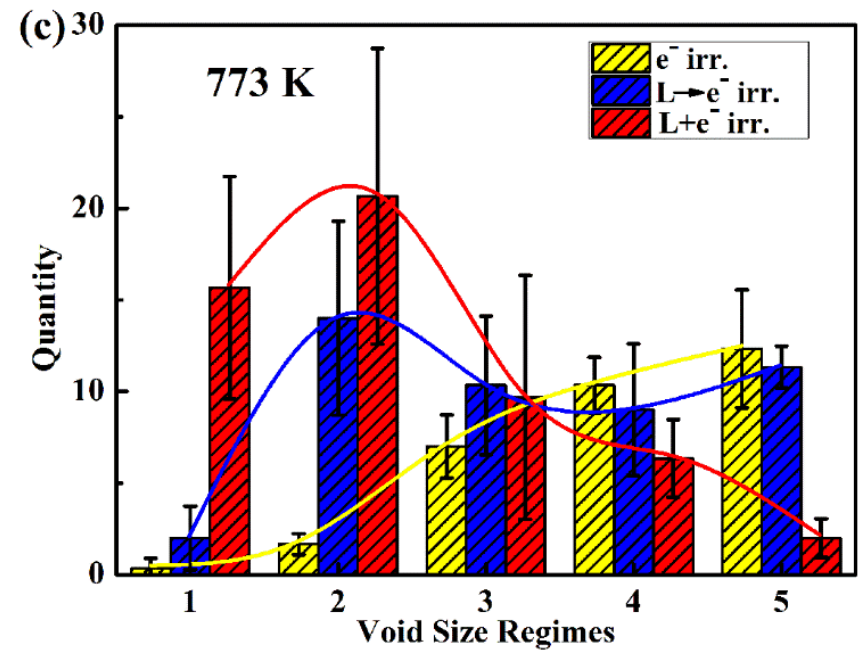

Figure 3(c) 


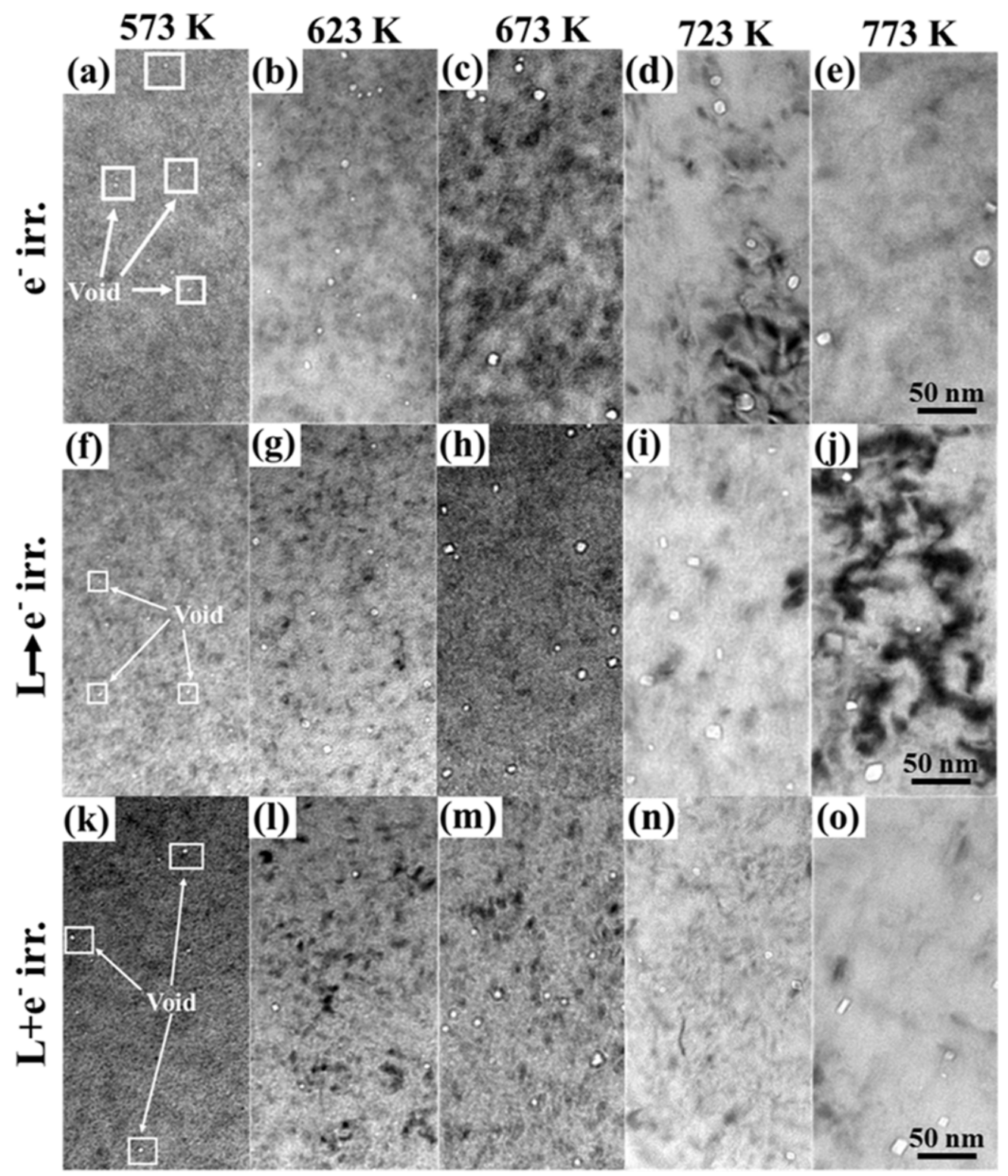

Figure 4

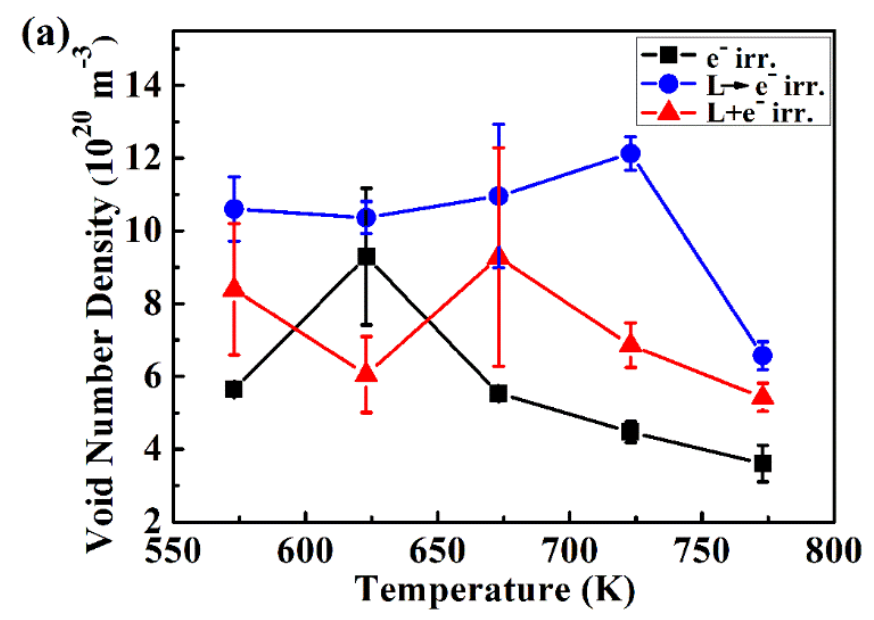

Figure 5(a) 


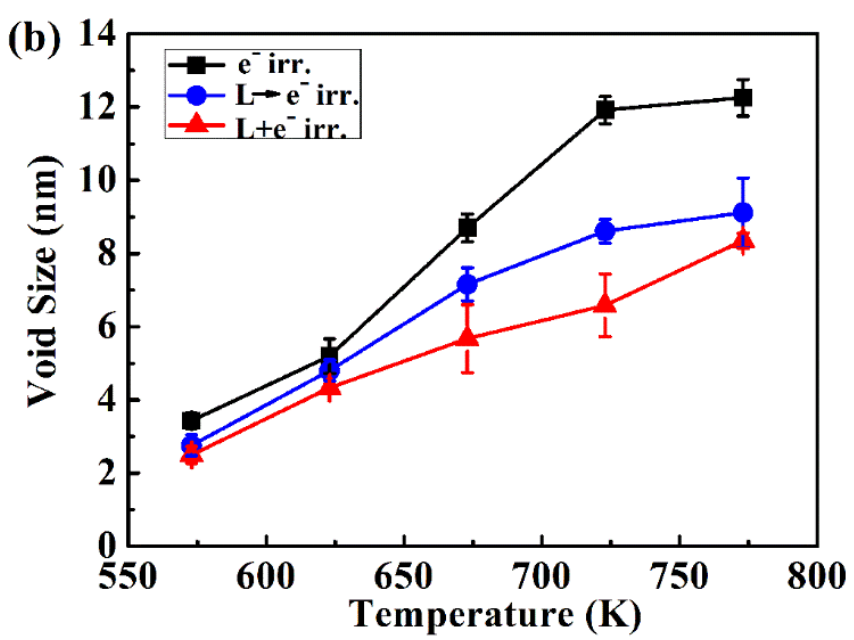

Figure 5(b)

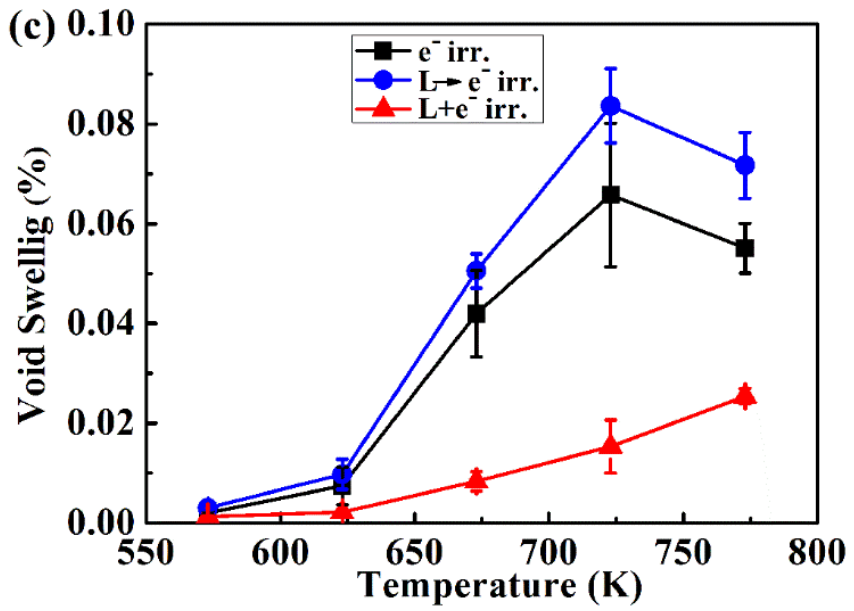

Figure 5(c) 